\title{
Histomorphological study of duodenum with special reference to RUT (Rapid Urease Test) negative dyspepsia in a rural care setting
}

\author{
Chattopadhyay P. ${ }^{1}$, Nayak P. ${ }^{2}$, Basak B. ${ }^{3}$ \\ ${ }^{1}$ Dr. Priyaranjan Chattopadhyay, Assistant Professor, ${ }^{2}$ Dr Pamela Nayak, Demonstrator, Department of Pathology, \\ Midnapore Medical College and Hospital, Paschim Medinipur, West Bengal, India, ${ }^{3}$ Dr. Bijan Basak, Associate \\ Consultant Pathologist, The Mission Hospital, Durgapur, West Bengal, India \\ Corresponding Author: Dr. Pamela Nayak, C/O Dr. Arabinda Nayak, Manoharchak, Contai, Purba Medinipur, West \\ Bengal, India. E-mail: pamela.nayak@gmail.com
}

\begin{abstract}
Introduction:In our institute duodenal biopsies are taken in patients having either, unexplained anemia, weight loss, recurrent loose stool, abdominal pain, dyspepsia or suspected malabsorption. In the present study we have evaluated histomorphological features of duodenal biopsies in patients presented with specifically Rapid Urease Test (RUT) negative dyspepsia. Materials and Methods: A retrospective observational study was conducted and data of duodenal biopsies were collected from January 2017 to December 2018. Histopathology slides of duodenal biopsies were reevaluated. We have correlated clinical and endoscopic findings with various histomorphological parameters. Results: We have included total 99 cases. Demographic profile of our study population shows wide age range (9 years to 74 years) with mean age 39.8 years and Male: Female ratio 1.1:1. Dyspepsia was the common presenting symptoms $(64.6 \%$ cases) and malabsorption was suspected in 29 cases. $28.3 \%$ cases show villous architectural abnormalities which correlate significantly with endoscopic findings of duodenal nodularity. Moderate to severe lamina propria lymphoplasmacytic infiltration seen in 58.56\% cases and correlates significantly with dyspeptic symptoms. Duodenal biopsy was diagnostic in 3\% cases. Conclusion: Diagnostic yield of duodenal biopsy is low but informative with proper clinical background.
\end{abstract}

Keywords: Duodenal biopsy, Dyspepsia, Malabsorption

\section{Introduction}

Endoscopist takes duodenal biopsy during upper GI endoscopy in context of various symptomology like suspected malabsorption, evaluation of chronic and intermittent diarrhea, iron deficiency anemia evaluation, diagnosis and monitoring of gluten sensitive enteropathy and diagnosis of neoplasia \& dyspepsia [1, 2]

Malabsorption is defined as chronic or intermittent diarrhea lasting for more than 4 weeks with diminished absorption of one or more nutrients. Physicians diagnosed malabsorption when any of the following features were present: diarrhea, steatorrhea, weight loss, edema and or clinical features suggestive of nutritional deficiency [3]. Dyspepsia refers to presence of one or more of the following symptoms like postprandial fullness, early satiation, epigastric pain or epigastric burning sensation [4].

Manuscript received: $10^{\text {th }}$ May 2019

Reviewed: $20^{\text {th }}$ May 2019

Author Corrected: $25^{\text {th }}$ May 2019

Accepted for Publication: $1^{\text {st }}$ June 2019
Functional dyspepsia found in majority of patients undergoing endoscopy; Helicobacter Pylori causes a small percentage of cases [5].

The present study assessed the histomorphological change according to symptomatology and various etiologies in the study population. Aim of our study is to correlate morphological changes with various symptoms specifically dyspepsia.

\section{Material and Methods}

Study Design: Retrospective observational study Duration of study: 2 years (January 2017 to December 2018)

Place of study: A tertiary care center serving rural population.

Method of data collection: Data of all duodenal biopsy cases were collected from the register. Hematoxylin \& Eosin stained slides of duodenal biopsy cases were retrieved from the archive and reviewed. 
Special stains like Giemsa stain, Periodic Acid Schiff stain was performed from retained block as required. We have included cases of all age and sex whose clinical data and duodenal biopsy slides were available.

Exclusion criteria: we have excluded cases having incomplete clinical profile, poorly oriented biopsy in histopathology slides, and rapid urease test positive cases.

Data analysis: Cases were evaluated on the basis of their clinical profile (like age, sex), clinical presentations, endoscopic findings and histopathological features. We have reviewed the histopathology slides stained with Hematoxylin \& Eosin for features like villous architecture, villous crypt ratio, lamina propria inflammation, IEL (Intraepithelial

\section{Original Research Article}

lymphocytes) at villous tip, presence of neutrophil and eosinophils in lamina propria and presence of microorganism. We have done the subjective grading of lamina propria inflammation to mild, moderate and severe grade. We have counted intraepithelial lymphocytes in 100 enterocytes of 5 villous tips.

Ethical consideration and permission: We have taken permission from Institutional Ethics Committee before conducting this study.

Statistical Analysis: We analyzed the collected data statistically in suitable software. We have correlated the clinical symptoms with the histomorphological features. Chi square test was applied to find out significance of difference and $\mathrm{P}$ value $<0.05$ was considered as significant.

\section{Results}

Age and Sex Distribution: Age range is 9 years to 74 years of present study population with mean age 39.8 years. Majority (40.4\%) cases are from the age range of 21 - 40 years. There is slight male predominance with Male: Female ratio 1.1:1 (Table 1)

Table-1: Age and sex distribution $(n=99)$

\begin{tabular}{|c|c|c|c|}
\hline \multirow{2}{*}{ Age } & \multicolumn{2}{|c|}{ Sex } & \multirow{2}{*}{ Total } \\
\cline { 2 - 4 } & Male & Female & 16 \\
\hline$</=20$ years & 8 & 8 & 40 \\
\hline $21-40$ years & 15 & 25 & 29 \\
\hline $41-60$ years & 19 & 10 & 14 \\
\hline$>60$ years & 10 & 4 & $\mathbf{9 9}$ \\
\hline Total & $\mathbf{5 2}$ & $\mathbf{4 7}$ & \\
\hline
\end{tabular}

Clinical Presentation: Dyspepsia (64.6\%) was the most common presenting symptoms followed by recurrent abdominal pain (36.4\%), recurrent loose stool (16\%), altered bowel habit and anemia (Table 2). Multiple symptoms are present in fair number of cases. Malabsorption was suspected in $29(29.3 \%)$ cases.

Table-2: Distribution of Clinical Presentation

\begin{tabular}{|c|c|c|}
\hline Clinical presentation & Number of cases & Percentage \\
\hline Dyspepsia & 64 & $64.6 \%$ \\
\hline Recurrent abdominal pain & 36 & $36.4 \%$ \\
\hline Recurrent loose stool & 16 & $16 \%$ \\
\hline Altered bowel habit & 4 & $4 \%$ \\
\hline Anemia & 3 & $3 \%$ \\
\hline
\end{tabular}

Endoscopic Findings: Endoscopic findings were available in 66 cases. Common findings were corpus predominant gastritis (29\%), erosive duodenitis (19.7\%), duodenal nodule (16.6\%), erosive gastritis, antral gastritis etc. Other findings include pangastritis, fundal gastritis, duodenal ulcer, flattening of duodenal mucosa, polypoid lesion at duodenum, loose lower esophageal sphincter.

Site of Duodenal Biopsy: Data on site of duodenal biopsy was available in 52 cases and in majority (84\%) the site was second part of duodenum. Only in few cases biopsy was taken from first part of duodenum (8\%) or both first and second part of duodenum (4\%) or junction of first and second part of duodenum (4\%). 


\section{Original Research Article}

Villous Architecture: Majority of cases (71.7\%) villi are long and slender. Abnormal villous architecture are seen in 28 (out of 99) cases. Common villous architectural abnormalities are shortening of villous (39\%), broad villi (27.5\%) followed by villous atrophy (17\%), focal villi fusion (17\%), partial villi erosion (14\%). Other findings include villi branching, damaged surface enterocytes etc. Overlapping features are also noted in few cases. (Image 1)

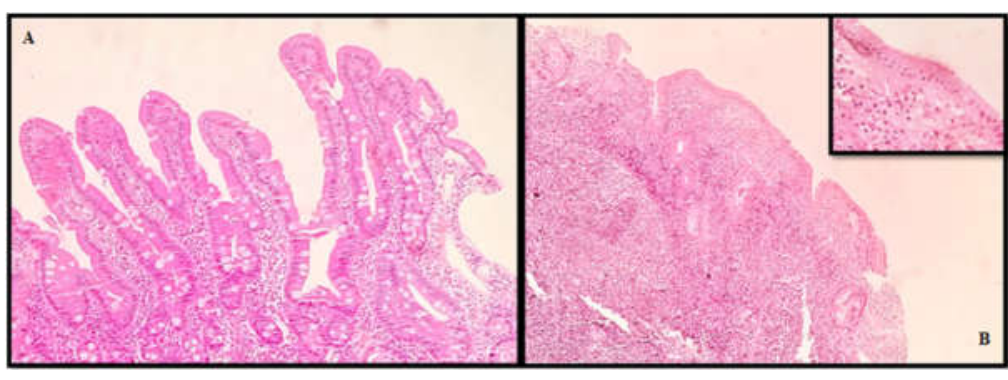

Image 1: (A) Normal duodenal biopsy showing long slender villi (100

v marnifinations HRrF atain) (R) Musdanal hisnor shorrina carara

An endoscopic finding of duodenal nodularity correlates significantly ( $\mathrm{P}$ Value $<0.05$ ) with villous architectural abnormality.

Villous abnormality in the form of shortening of villi, partial villous atrophy, villi erosion, fusion of villi seen in 8 out of 29 cases of suspected malabsorption but this is not statistically significant (P Value 0.92)

Lamina Propria Inflammation: Lympho-plasmacytic infiltration at lamina propria was graded as mild moderate and severe (subjective grading). Moderate and severe inflammation accounts for around $58.56 \%$ cases. Rest of the cases has mild inflammation or normal findings (Diagram 1). Neutrophilic infiltration noted in $7 \%$ cases and eosinophils present in $4 \%$ cases at lamina propria.

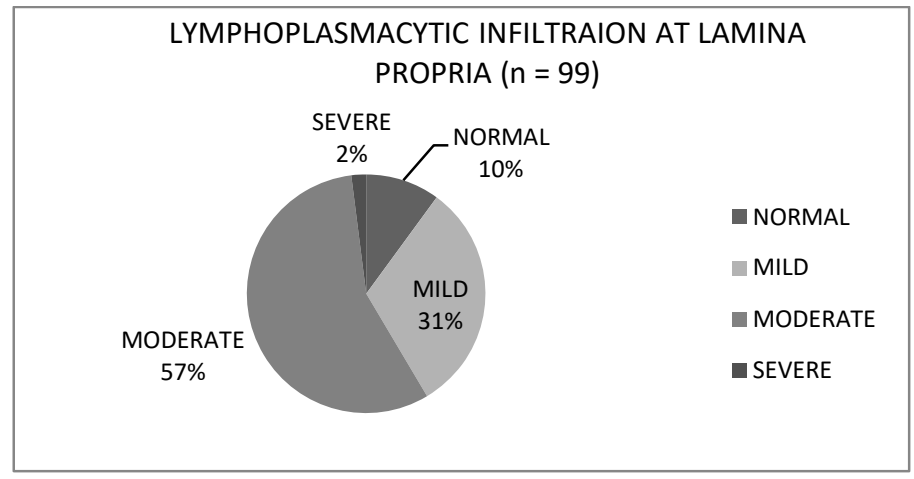

Diagram-1: Lympho-Plasmacytic Infiltration at Lamina Propria

We have correlated lamina propria inflammation with dyspepsia and there is significant moderate or severe lamina propria inflammation in patients with dyspepsia $(\mathrm{P}$ value $<0.05)$.

Table-3: Duodenal Biopsy Interpretation

\begin{tabular}{|c|c|c|}
\hline Duodenal biopsy interpretation & No. of cases & Percentage \\
\hline Normal & 30 & $30.30 \%$ \\
\hline Normal villi with moderate lympho-plasmacytic infiltration at lamina propria & 33 & $33.33 \%$ \\
\hline Non-specific duodenitis & 21 & $21.21 \%$ \\
\hline Brunners gland hyperplasia & 5 & $5.05 \%$ \\
\hline Crohn's disease & 1 & $1.01 \%$ \\
\hline Celiac disease & 1 & $1.01 \%$ \\
\hline Non-hodgkins lymphoma & 1 & $1.01 \%$ \\
\hline Others & 7 & $7.07 \%$ \\
\hline Total & $\mathbf{9 9}$ & $\mathbf{1 0 0} \%$ \\
\hline
\end{tabular}




\section{Original Research Article}

Intraepithelial Lymphocytes: Intraepithelial lymphocytes (IEL) range from 2 to 25 in present study with mean IEL 5.5 .

Duodenal Biopsy Interpretation: Duodenal biopsy was diagnostic in 3 cases (3.33\%). 21 cases show features of nonspecific duodenitis and 5 cases show brunner's gland hyperplasia. 30 cases were normal and rest of the cases show non-specific findings (Table 3)

\section{Discussion}

The issue of performing a routine duodenal biopsy is controversial [1] and justifiable to cost benefit ratio. However many studies have shown the unsuspected duodenal pathology in routine duodenal biopsies $[6,7]$

In present study, the commonest clinical presentation of duodenal biopsy cases were dyspepsia, recurrent abdominal pain, loose stool etc. which is quite similar to study conducted in Mayo clinic where chronic dyspepsia (46\%) and diarrhea (35\%) were the commonest indication for duodenal biopsy.(8)In Burger et al study also the common indications were dyspepsia, anemia, weight loss, diarrhea etc [9]

In our study population, mean age for undergoing upper gastrointestinal endoscopy with duodenal biopsy was 39.8 years and Male: Female ratio was 1.1:1. These findings are similar to another study conducted in India by Basavaraj et a 1(10) where mean age was 38.25 with slight male predominance, but study from Mayo clinic and Burger et al studyhave mean age slightly higher (50 years 54.6 years respectively) with female predominance $[8,9]$. However Stanghellini $\mathrm{V}$ et al demonstrated that Helicobacter pylori (H pylori) negative dyspeptic patients are younger when compared to $\mathrm{H}$ pylori positive cases with male predominance[11]

As per diagnostic yield was concern, duodenal biopsy was diagnostic in 3 cases. We reported one case of celiac disease (confirmed with transglutaminase positivity). Apart from this, two clinically suspected cases of Non-Hodgkin's Lymphoma and Crohn's disease were confirmed by duodenal biopsy histopathology.

A regional difference in celiac disease is attributed to genetic, dietary and immunological factors; most of the cases were from states of North India possibly due to high wheat consumption [12, 13]. However, A study from south India with 101 patients of malabsorption, reported prevalence of celiac disease was $15.8 \%$. (14) Major histopathological features of untreated celiac disease in duodenal biopsies are intraepithelial lymphocytosis, increased number of inflammatory cells at lamina propria and villous atrophy [15]. Howeverdiagnostic yield of routine duodenal biopsy for celiac disease was low as reported by Castro $\mathrm{F}$ et al, Stoven SA et al $[8,16]$.
In present study, villi architecture was normal in 71 (71.7\%) cases. Earlier studies by Balasubramanian P et al (14) reported normal villi architecture in $40.6 \%$ cases. Endoscopic duodenal nodularity was found in $16.6 \%$ cases in our study which are quite similar to study conducted by Castro F et al [16].

In present study, endoscopic duodenal nodularity correlates significantly with villous architectural abnormality. Zukerman GR et al study also found villous blunting and thickening in several duodenal biopsies taken in endoscopic nodular duodenitis cases [17]. Another study conducted among children (6 - 17 years) from India show presence of villous atrophy in $47 \%$ cases of duodenal nodularity [18].

In our study moderate to severe lamina propria lymphoplasmacytic infiltration was found in $58.56 \%$ cases and correlate significantly ( $\mathrm{P}$ value $<0.05 \%$ ) with dyspeptic symptoms.According to Collins et al study also Helicobacter Pylori negative dyspepsia (non-ulcer dyspepsia) cases have higher mononuclear cell counts compare to control group [19].

Li et al study in patients with nodular duodenitis demonstrated significant chronic inflammation in $\mathrm{H}$ pylori negative cases compared to control [20]. Moderate to severe lamina propria lympho-plasmacytic cell infiltration seen in variety of conditions including celiac disease, peptic duodenitis, non-specific duodenitis, drug and infection [21].

New insights have been come in pathogenesis and significance of duodenal inflammation in dyspepsia (functional). Recent studies indicated "gut brain microbial axis" [22] and persistent of duodenal inflammation in post infection [23] as potential role in dyspepsia.

\section{Conclusion}

In proper clinical setting duodenal biopsies are informative and in selected situation also diagnostic. A significant lamina propria lympho-plasmacytic infiltration seen among patient presented with rapid urease test negative dyspepsia may actually strengthening "gut brain microbial axis" hypothesis and need further study in this area. 
Findings: Nil; Conflict of Interest: None initiated Permission from IRB: Yes

Authorship Contributions: Concept- Priyaranjan Chattopadhyay (P.C.), Pamela Nayak (P.N.), Bijan Basak (B.B.); Design P.C., P.N.; Supervision - B.B.; Materials- P.C., P.N., B.B.; Data collection \&/or processing- P.C., P.N.;B.B., Analysis and/or interpretation - P.C., P.N.; Literature search; P.C., P.N.; Writing - P.C., P.N., Critical review - P.C., P.N., B.B.

\section{References}

1. Serra S, Jani PA. An approach to duodenal biopsies. J Clin Pathol. 2006 Nov;59(11):1133-50. Epub 2006 May 5. DOI:10.1136/jcp.2005.031260.

2. Talley NJ. American Gastroenterological Association Medical Position Statement: Evaluation of Dyspepsia. Gastroenterology. 2005;129(5):1753-5 DOI: 10.1053/j. gastro.2005.09.019 Available from: https://doi.org /10.1053/j.gastro. 2005.09.019.

3. Riley S, Marsh M. Maldigestion and Malabsorption. Sleisenger and Fordtran's, Gastrointestinal and Liver Disease, Pathophysiology/ Diagnosis/ Management. Volume 2. 6th Edition ed: W.B. Saunders company; 1998. p. $1501-22$

4. Talley NJ, Stanghellini V, Heading RC, et al. Functional gastroduodenal disorders. Gut. 1999 Sep;45 Suppl 2:II37-42. DOI:10.1136/gut.45.2008.ii37.

5. Moayyedi P, Deeks J, Talley NJ, et al. An update of the Cochrane systematic review of Helicobacter pylori eradication therapy in nonulcer dyspepsia: resolving the discrepancy between systematic reviews. Am J Gastroenterol. 2003 Dec;98(12):2621-6. DOI:10.1111/j. 1572-0241.2003.08724.x.

6. Kori M, Gladish V, Ziv-Sokolovskaya N, et al. The significance of routine duodenal biopsies in pediatric patients undergoing upper intestinal endoscopy. J Clin Gastroenterol. 2003 Jul;37(1):39-41.

7. Hopper AD, Cross SS, McAlindon ME, et al. Symptomatic giardiasis without diarrhea: further evidence to support the routine duodenal biopsy? Gastrointest Endosc. 2003 Jul;58(1):120-2. DOI:10.1067/mge.2003.199.

8. Stoven SA, Choung RS, Rubio-Tapia A, et al. Analysis of Biopsies From Duodenal Bulbs of All Endoscopy Patients Increases Detection of

\section{Original Research Article}

Abnormalities but has a Minimal Effect on Diagnosis of Celiac Disease. Clin Gastroenterol Hepatol. 2016 Nov;14 (11): 1582-1588. doi: 10.1016/j.cgh. 2016.02. 026. Epub 2016 Mar 7.

9. Burger JP, Meijer JW, Wahab PJ. Routine duodenal biopsy to screen for coeliac disease is not effective. The Netherlands journal of medicine. 2013;71(6):308-12 Available from: http://www.njmonline.nl/ getpdf .php? $\mathrm{id}=1331$.

10. Basavaraj A, Kulkarni R, Kadam D, Thorat V. Clinicohistopathological correlation and $<\mathrm{i}>$ Helicobacter pylori $</ \mathrm{i}>$ status in patients with functional dyspepsia. Medical Journal of Dr DY Patil University. 2017;10 (3): 257-62 DOI: 10.4103/09752870.206571

11. Stanghellini V, Tosetti C, De Giorgio R, Barbara G, Salvioli B, Corinaldesi R. How should Helicobacter pylori negative patients be managed? Gut. 1999;45 Suppl 1(Suppl 1):I32-5 DOI: 10.1136/gut.45.2008.i32 Available from: https:/gut.bmj.com/content/ gutjnl/45/ suppl_1/I32.full.pdf.

12. Gupta R, Reddy DN, Makharia GK, Sood A, Ramakrishna BS, Yachha SK, et al. Indian task force for celiac disease: current status. World journal of gastroenterology. 2009;15(48):6028-33 DOI: 10.3748/wjg. 15.6028

13. Makharia GK, Verma AK, Amarchand R, et al. Prevalence of celiac disease in the northern part of India: a community based study. J Gastroenterol Hepatol. 2011 May;26 (5):894-900. doi: 10.1111/j. 1440-1746.2010.06606.x.

14. Balasubramanian $\mathrm{P}$, Badhe BA, Ganesh RN, et al. Morphologic Spectrum of Duodenal Biopsies in Malabsorption: A Study from Southern India. J Clin Diagn Res. 2017 Jul;11(7):EC17-EC21. doi: 10.7860/ JCDR/ 2017/23871.10231. Epub 2017 Jul 1.

15. Owen DR, Owen DA. Celiac Disease and Other Causes of Duodenitis. Archives of pathology \& laboratory medicine. 2018;142(1):35-43 DOI: 10.5858/arpa.2016-0608-RA

16. Castro F, Shiroky J, Raju R, Lurix E, Erim T, Johnston Y, et al. Routine Duodenal Biopsies in the Absence of Endoscopic Markers of Celiac Disease Are Not Useful: An Observational Study. ISRN Endoscopy. 2013;2013:5 DOI: 10.5402/2013/623936 Available from: http://dx.doi.org/10.5402/2013/623936. 
17. Zukerman GR, Mills BA, Koehler RE, et al. Nodular duodenitis. Pathologic and clinical characteristics in patients with end-stage renal disease. Dig Dis Sci. 1983 Nov;28(11):1018-24.

18. Gonul CD, Bilge C, Gazi KA, Filiz K. Duodenal nodularity in children: a clinical and pathologic study of 17 cases. Indian journal of pathology \& microbiology. 2011;54 (2):312-7 DOI: 10.4103/0377-4929.81611

19. Collins JS, Hamilton PW, Watt PC, Sloan JM, Love AH. Quantitative histological study of mucosal inflammatory cell densities in endoscopic duodenal biopsy specimens from dyspeptic patients using computer linked image analysis 1990 [updated AugPMC1378609]. 1990/08/01:[858-61]. Available from: https:/gut.bmj.com/content/31/8/858.long.

20. Li XB, Ge ZZ, Chen XY, Liu WZ. Duodenal gastric metaplasia and Helicobacter pylori infection in patients with diffuse nodular duodenitis. Brazilian journal of

\section{Original Research Article}

medical and biological research $=$ Revista brasileira de pesquisas medicas e biologicas. 2007;40(7):897-902 DOI: $10.1590 / \mathrm{s} 0100-879 \times 2006005000117$ Available from: http://dx.doi.org/10.1590/ S0100-879X20060 05000117

21. Fenoglio-Preiser CM, Noffsinger AE, Stemmermann GN, Lantz PE. Gastrointestinal Pathology: An Atlas and Text: Wolters Kluwer Health/ Lippincott Williams \& Wilkins; 2008.

22. Lee YY, Chua AS. Influence of gut microbes on the brain-gut axis (Gut 2011;60:307-317). J Neurogastroenterol Motil. 2011 Oct; 17 (4):427-9. doi: 10.5056/jnm. 2011.17.4.427. Epub 2011 Oct 31.

23. Li X, Chen H, Lu H, et al. The study on the role of inflammatory cells and mediators in post-infectious functional dyspepsia. Scand J Gastroenterol. 2010 May;45(5):573-81. doi: 10.3109/00365521003632576.

\section{How to cite this article?}

Chattopadhyay P., Nayak P., Basak B. Histomorphological study of duodenum with special reference to RUT (Rapid Urease Test) negative dyspepsia in a rural care setting. Trop J Path Micro 2019;5 (6): 349-354. doi:10.17511/jopm.2019.106.03. 